\title{
Bone Cancer pN0 TNM Finding v7
}

National Cancer Institute

\section{Source}

National Cancer Institute. Bone Cancer pNO TNM Finding v7. NCI Thesaurus. Code C88433.

Bone cancer without regional lymph node metastasis. (from AJCC 7th Ed.) 